\title{
TREATMENT OF RENAL TRANSPLANT STONES BY EXTRACORPOREAL SHOCK-WAVE LITHOTRIPSY IN THE PRONE POSITION
}

\author{
MICHAEL WHEATLEY, M.D. \\ STEPHEN C. WANG, M.D. \\ DANA A. OHL, M.D. \\ JOHN W. KONNAK, M.D. \\ L. PAUL SONDA, III, M.D. \\ From the Department of Surgery, Section of Urology, \\ University of Michigan Medical Center, Ann Arbor, Michigan
}

ABSTRACT-Two patients with renal transplant lithiasis were successfully treated with extracor-
poreal shock-wave lithotripsy (ESWL) in the prone position. Pathogenesis and treatment of trans-
plant lithiasis are discussed. Performing ESWL on renal transplant patients in the prone position
has advantages over standard positioning techniques.

Lithiasis is an unusual complication of renal transplantation, occurring in $0.2-1.0$ percent of transplants. ${ }^{1-4}$ Several different approaches have been advocated for the management of allograft calculi including endourologic extraction and surgical removal of symptomatic stones. A recent report described the use of a combination extracorporeal shock-wave lithotripsy (ESWL) and percutaneous techniques in treating a renal transplant stone, using the "blast-path" technique of positioning. ${ }^{5}$ By performing ESWL, we were successful in removing renal transplant stones in 2 patients in the prone position without the use of percutaneous nephrostomy.

\section{Case Reports}

\section{Case 1}

A twenty-year-old woman was diagnosed with severe focal necrotizing glomerulonephritis at age twelve. Hemodialysis was instituted at age fifteen, and at eighteen, she underwent cadaveric renal transplantation with her postoperative serum creatinine stabilizing at $1.5 \mathrm{mg} / \mathrm{dL}$. External ureteroneocystostomy was used for ureteral anastomosis. In her first postoperative month, persistent microscopic hematuria prompted evaluation. An intravenous pyelogram with tomography revealed a calculus in an upper pole calyx of the transplanted kidney without any evidence of obstruction (Fig. 1A, B). Because of absence of symptoms, no further treatment was instituted at that time.

She did well until twenty months postoperatively when Escherichia coli urosepsis developed. Her stone had not changed in location on $x$-ray studies, and she responded rapidly to intravenous antibiotics. No stone treatment was instituted at that time. Two months later however she was admitted again with pyelonephritis. Evaluation of her recurrent urosepsis revealed that the calculus had moved into the ureteropelvic junction of the transplant (Fig. $1 \mathrm{C}$.

She underwent placement of a $4.8 \mathrm{~F}$ Double-J ureteral stent and ESWL therapy. The ESWL treatment was carried out in the prone position with the Dornier HM-3 lithotriptor, utilizing the Stryker frame modification as described by Jenkins and Gillenwater. ${ }^{6}$ A total of 2,000 shocks at $18 \mathrm{kv}$ were delivered.

Postoperative ultrasound confirmed fragmentation of the stone and follow-up plain $\mathrm{x}$ ray film (KUB) and tomography confirmed 

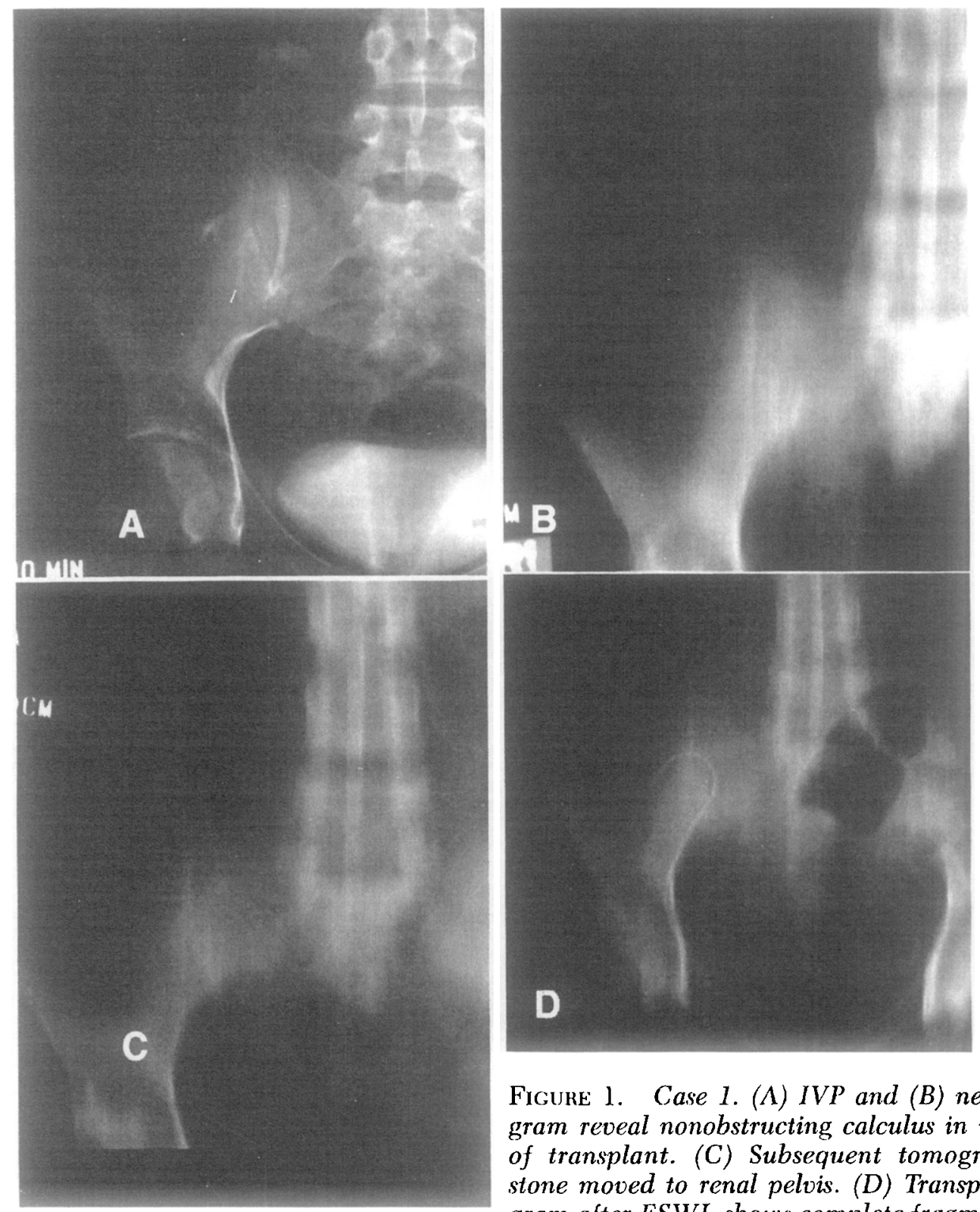

Figure 1. Case 1. (A) IVP and (B) nephrotomogram reveal nonobstructing calculus in upper pole of transplant. (C) Subsequent tomogram shows sione moved to renal pelvis. (D) Transplant tomogram after ESWL, shows complete fragmentation of stone.

complete disintegration of the stone (Fig. ID). Her postoperative course was marked by hematuria and pain over the allograft immediately following ESWL. This rapidly resolved, and she was discharged one week postoperatively with a creatinine of $2.1 \mathrm{mg} / \mathrm{dL}$. The ureteral stent spontaneously passed with voiding. She is now four months post-ESWI, and remains asymptomatic and without recurrent stones. Presently, her serum creatinine is $1.6 \mathrm{mg} / \mathrm{dL}$.

\section{Case 2}

In 1969 , after passing multiple calcium oxalate stones, a twenty-seven-year-old man was found to have primary hyperoxaluria, with an oxalate excretion of $178 \mathrm{mg} / 24^{\circ}$. He was given high-dose pyridoxine therapy for this. In 1982, he presented with symptoms of uremia and a creatinine of $25.6 \mathrm{mg} / \mathrm{dL}$. Evaluation revealed very small calcified kidneys and hemodialysis was begun. In 1985, he received a cadaveric renal transplant. External ureteroneocystostomy. was used for ureteral transplantation. He was: managed initially with cyclosporine, but this was changed to azathioprine and prednisone. due to cyclosporine toxicity. His baseline creatinine on stable immunosuppression was $2.0 \mathrm{mg} / \mathrm{dL}$. 


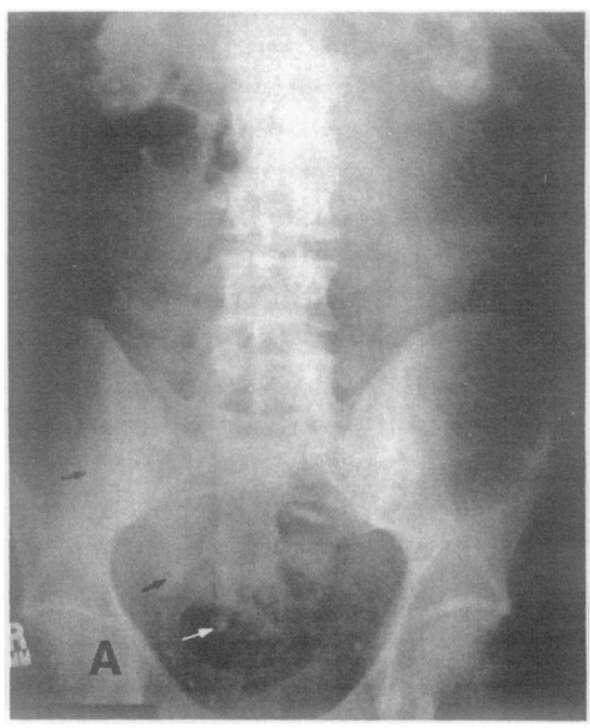

Figure 2. Case 2. (A) Abdominal $x$-ray film shows calcified native kidneys and transplant with multiple renal and ureteral stones. (B) Steinstrasse in distal ureter following ESWL. (C) Follow-up abdominal $x$-ray film shows all stone fragments have passed.

He presented in 1988 at the age of forty-six with a creatinine of $2.5 \mathrm{mg} / \mathrm{dL}$. An ultrasound and KUB film revealed multiple stones in the transplant with a stone obstructing the ureter (Fig. 2A). Under epidural anesthesia, attempts were made to catheterize the ureter with rigid and flexible cystoscopes. This was impossible due to the high location of the anastomosis on the dome of the bladder and the tortuous course of the ureter. He then underwent ESWL in the prone position. A total of 2,500 shocks at $21 \mathrm{kv}$ were distributed among the visible stones, concentrating on the obstructing lower ureteral stone. Localization was aided by bladder contrast medium placed through a Foley catheter, and oblique films taken preoperatively to simulate the angle of the lithotriptor fluoroscopy units.

Postoperatively, he had mild pain in the right lower quadrant, but no other symptoms. His postoperative KUB film showed fragmentation of the stones and development of steinstrasse in the distal ureter (Fig. 2B). An ultrasound showed improvement of the hydronephrosis. Creatinine at the time of his discharge was 2.1 $\mathrm{mg} / \mathrm{dL}$. A follow-up KUB film two weeks later demonstrated that all stone fragments had been passed, and his serum creatinine at that time was $1.7 \mathrm{mg} / \mathrm{dL}$.
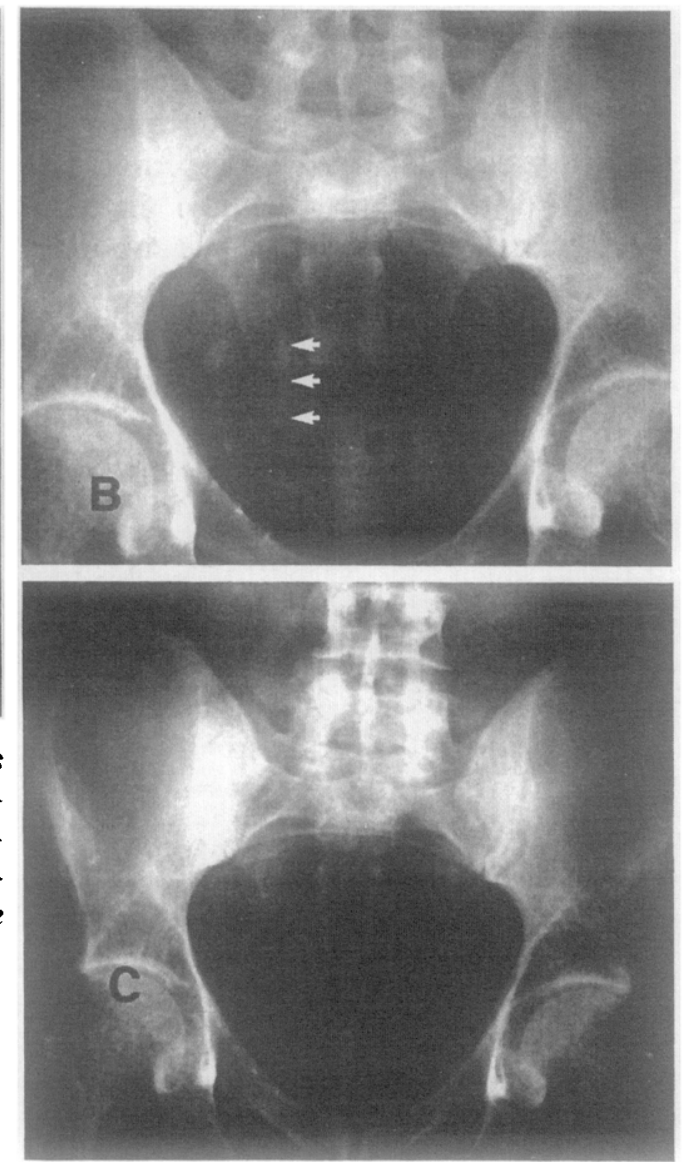

\section{Comment}

Renal transplant lithiasis is usually a late complication, often occurring at least six months after transplantation. ${ }^{1,2,7 \cdot 10}$ In most cases, an underlying cause can be identified. Predisposing conditions include: ureteral stricture, commonly at the ureteral anastomosis; hypercalcemia secondary to hyperparathyroidism, glucocorticoid administration, or hypophosphatemia from overaggressive antacid therapy; chronic infection; use of nonresorbable suture for the ureteral anastomosis; metabolic disease such as primary hyperoxaluria; and distal renal tubular acidosis which is commonly seen in the post-transplant kidney.,10

Donor graft lithiasis is another form of allograft lithiasis, occurring when a donor kidney with an unsuspected calculus is transplanted. The incidence of this problem only can be estimated since these stones may be asymptomatic or may be diagnosed several years after transplantation when complications arise. Van Gansbeke et al. ${ }^{3}$ estimate the incidence by reasoning that asymptomatic stones are detected 
by scout radiographs in 0.37 percent of kidneys in a general population, and therefore, 0.37 percent of donated kidneys will have stones. This estimate correlates with the incidence of 0.46 percent of donor graft lithiasis in their series of 439 transplants and with the reported incidence of 0.40 percent in the Lerut et al..$^{4}$ series of 248 renal transplants. Given this incidence of donor graft lithiasis, a screening radiograph of all cadaver donor kidneys may be warranted to rule out preexisting calculi. If found, these may be removed at the time of transplantation.

The diagnosis of allograft lithiasis is usually easily made once complications arise. Plain abdominal radiographs, transplant ultrasound, tomography, and antegrade and retrograde contrast studies may aid in diagnosing and localizing the stones in the transplanted kidney.

Complications related to renal transplant lithiasis can vary in severity. Allograft calculi may be discovered on routine transplant followup, and in many cases, no treatment may be necessary. However, hydronephrosis, urinary tract infections, and allograft failure from obstruction may occur. Therefore patients with stones in whom no treatment is given must be followed closely. Treatment options for transplant calculi include extraction via percutaneous nephrostomy tract ${ }^{8,9,11}$ and surgical removal.

ESWL provides an alternative to these invasive methods of treating renal transplant calculi. Due to the location of the transplanted kidney in the pelvis, alterations in positioning of patients in the water bath must be made to allow optimum localization of the stones. The standard method of positioning the patient on a gantry in a modified semi-Fowler's position results in diminution of the shock-wave force through the bony pelvis. ${ }^{12}$ Also, due to the anterior position of the transplant kidney, it is difficult to bring the collecting system into the $F_{2}$ focus in the supine position. This problem was partially circumvented by utilizing the "blastpath" technique in a recent report by Locke et al. ${ }^{5}$ Because of these problems, it is advantageous to treat transplant kidneys with the patient in the prone position.

The use of a ureteral stent allowed more accurate localization of the stone in Case 1. Localization was more difficult in Case 2 in whom we were unable to pass a stent because of the bladder dome location of the ureteroneocystostomy. Although we $\mathrm{e}^{13}$ prefer the external ureteroneocystostomy in renal transplantation, it might be prudent to perform an anastomosis which is easier to cannulate in patients expected to have recurrent stone problems, such as those with primary hyperoxaluria.

Our first patient's creatinine rose slightly from $1.5 \mathrm{mg} / \mathrm{dL}$ to $2.1 \mathrm{mg} / \mathrm{dL}$ after the procedure and did not return to baseline until four months after the procedure. The rise in creatinine was seen in conjunction with ESWL, although an acute deterioration in renal function is not commonly associated with the procedure. The long-term effects of ESWL on the transplanted kidneys are unknown, but hopefully it will prove as safe in treating transplant lithiasis as it has for the treatment of native kidney stones.

Lithiasis in a renal allograft remains an uncommon complication of kidney transplantation. When present, however, invasive extraction via endourologic or surgical techniques has often been necessary. ESWL offers an alternative, noninvasive method for treating transplant lithiasis. We believe ESWL on a transplant is most easily performed with the patient in prone position as described.

1500 E. Medical Center Drive 2916 Taubman Center, Box 0330; Ann Arbor, Michigan 48109:

(DR. OHL)

\section{References}

1. Mundy AR, et al: The urological complications of $1,000 \mathrm{re}$; nal transplants, Br J Urol 53: 397 (1981).

2. Starzl TE, et al: Urologic complications in 216 human recip ients of renal transplants, Ann Surg 172: 1 (1970).

3. Van Gansbeke D, et al: Lithiasic complications of renal transplantation: the donor graft lithiasis concept, Urol Radiol 7 157 (1985).

4. Lerut J, Lerut 'I, Gruwez JA, and Michielsen I': Case prot file: Donor graft lithiasis-unusual complication of renal trans plantation, Urology 14: 627 (1979).

5. Locke DR, et al: Combination of extracorporeal shock-wave lithotripsy and percutaneous extraction of calculi in a renal allo graft, J Urol 139: 575 (1988).

6. Jenkins $A D$, and Gillenwater JY: Extracorporeal shock wave lithotripsy in prone position: treatment of stones in distay ureter on anomalous kidney, J Urol 139: 911 (1988).

i. Stuck KJ, et al: Ultrasound evaluation of uncommon rendl transplant complications, Urol Radiol 8: 6 (1986).

8. Eshghi M, and Smith AD: Endourologic approach to trans plant kidney, Urology' 28: 504 (1986).

9. Fisher $\mathrm{MF}$, et al: Renal stone extraction through a percutar neous nephrostomy in a renal transplant patient, Radiology 144 $95(1082)$

10. Rosenberg JC, et al: Calculi complicating a renal trans plant, Am J Surg 129: 326 (1975).

11. Jarowenko MV et al: Salvage of difficult transplant comiz plications by percutaneous techniques, J Urol 133: 840 (1985).

12. Chaussy CG, and Fuchs GJ: Extracorporeal shock-wave lithotripsy, 1987 Monogr Urol 8: 80 (1987).

13. Ohl DA, et al: External ureteroneocystostomy in reng/ transplantation, J Urol 139: 499 (1988). 